\title{
A TEMÁTICA AMBIENTAL NA FORMAÇÃO DE PROFESSORES NOS CURSOS DE LICENCIATURA DA UNIVERSIDADE FEDERAL DE RONDÔNIA: um estudo de caso no Campus de Porto Velho
}

\author{
Clarides Henrich de Barba ${ }^{1}$ \\ Rosa Maria Feiteiro Cavalari2
}

\section{RESUMO}

O artigo analisa a inserção da temática ambiental nos cursos de Licenciatura da Universidade Federal de Rondônia. Trata-se de um "estudo de caso", realizado por meio de análise documental dos projetos pedagógicos curriculares e dos planos das disciplinas de sete cursos de licenciatura, a saber: Pedagogia, Ciências Sociais, História, Geografia, Biologia, Química e Física que trabalham com a temática ambiental em seus currículos. Foram realizadas entrevistas "semidiretivas" com 14 (quatorze) professores desses cursos. Os dados foram analisados a partir da "Análise de conteúdo" de Bardin (2009), além das características de Ambientalização curricular elaboradas pela Rede ACES (2002). Os resultados revelam que os cursos de Licenciatura investigados privilegiam temas ambientais relacionados às questões amazônicas como o multiculturalismo ambiental, a biodiversidade, a espacialidade, a polvição e degradação da biodiversidade, da espacialidade e da territorialidade, da justiça ambiental, dos contextos históricos ambientais regionais. Constatou-se que os cursos contribuem para a formação de professores no campo da Educação Ambiental na Amazônia. Os currículos e as falas dos docentes evidenciam as seguintes características de Ambientalização Curricular: "compromisso com as transformações nas relações sociedade-natureza"; "contextualização local-global-local, global-local-global"; "levar em conta os participantes na construção do conhecimento" "considerar os aspectos cognitivos e afetivos, éticos e estéticos".

Palavras-chave: Temática ambiental no Ensino Superior. Formação de Professores. Educação ambiental.

\footnotetext{
1 Doutor em Educação (UNESP), Professor do Programa de Mestrado Acadêmico e Profissional em Educação da Universidade Federal de Rondônia, campus de Porto Velho, email: claridesbarba@gmail.com

2 Doutora em Educação (USP), Professora do Programa de Pós-graduação em Educação Escolar da Universidade Estadual de São Paulo (UNESP, campus de Rio Claro), e-mail: rosamfc@rc.unesp.br
} 


\title{
THE ENVIRONMENTAL THEME IN TEACHER'S TRAINING UNIVERSITY OF RONDÔNIA: a study in the Campus of Porto Velho
}

\begin{abstract}
In this article we analyze the insertion of the environmental theme in the undergraduate courses of the Federal University of Rondônia. This is a "case study", carried out through documentary analysis of the curricular pedagogical projects and the course plans of seven undergraduate programs: Pedagogy, Social Sciences, History, Geography, Biology, Chemistry and Physics which include the environmental theme in their curricula. Semi-directive interviews were conducted with 14 (fourteen) teachers of these courses. The data were analyzed from Bardin's "Content analysis" (2009), in addition to the characteristics of curricular Ambientalization elaborated by ACES Network (2002). The results show that the undergraduate courses which we investigated focus on environmental issues related to Amazonian region involving environmental multiculturalism, biodiversity, spatiality, pollution and degradation, biodiversity, spatiality and territoriality, environmental justice, regional historical environmental contexts. We verified that the undergraduate courses investigated train teachers and confirm that teachers' curricula and practices contribute to the training of teachers in the field of environmental education in the Amazon. The undergraduate courses show characteristics of Curricular Environmentalization related to the "commitment to the transformations of society-nature relations". We also perceive a "Local-global-local, global-local-global contextualization" in the courses. In addition, there is a commitment to "take into account the subject in the construction of knowledge" and to "consider cognitive and affective, ethical and aesthetic aspects" in the Environmental Studies.
\end{abstract}

Keywords: Environmental theme in Higher Education. Teacher training. Environmental Education.

\section{LA TEMÁTICA AMBIENTAL EN LA FORMACIÓN DE PROFESORES DE LAS CARRERAS DE LICENCIATURA DE LA UNIVERSIDAD FEDERAL DE RONDÔNIA: un estudio de caso en el campus de Porto Velho}

\section{RESUMEN}

El artículo analiza la inserción de la temática ambiental en los cursos de Licenciatura del campus de la Universidad Federal de Rondônia. Se trata de un "estudio de caso", realizado por medio de análisis documental de los proyectos pedagógicos curriculares y de los planes de las disciplinas de siete cursos de licenciatura, a saber: Pedagogía, Ciencias Sociales, Historia, Geografía, Biología, Química, Física; que trabajan con la temática ambiental en sus currículos.. Se realizaron entrevistas semidirectivas con 14 (catorce) profesores de estos cursos. Los datos fueron analizados a partir del "Análisis de contenido" de Bardin (2009), además de las características de Ambientalización curricular elaboradas por la Red ACES (2002). Los resultados revelan que los cursos de Licenciatura investigados privilegian temas ambientales relacionados con las cuestiones amazónicas como el multiculturalismo ambiental, la biodiversidad, la espacialidad, la contaminación y degradación, la biodiversidad, la 
espacialidad y la territorialidad, la justicia ambiental, los contextos históricos ambientales regionales. Se constató que los cursos contribuyen a la formación de profesores en el campo de la Educación Ambiental en el Amazonas.. Los cursos de licenciatura evidencian características de Ambientalización Curricular relacionadas al: "compromiso con las transformaciones en las relaciones sociedad-naturaleza"; "Contextualización local-global-local, global local-global"; "Tener en cuenta al sujeto en la construcción del conocimiento" "considerar los aspectos cognitivos y afectivos, éticos y estéticos".

Palabras clave: Temática ambiental en la enseñanza superior. Formación de profesores. Educación ambiental.

\section{INTRODUÇÃO}

Ao longo da história, os acontecimentos ambientais, provenientes de problemas causados pelo ser humano, têm sido alvo de preocupações cada vez maiores para a sociedade atual. Neste contexto, advindas da tecnologia mundial, as questões ligadas à natureza tornaram-se uma mercadoria no atual sistema capitalista e como tal causam prejuízos enormes à população.

Os problemas ambientais causados por acidentes nucleares, polventes químicos, derramamento de petróleo, indústrias de fertilizantes que não têm controle sobre o uso de agrotóxicos e contaminação de produtos hortigrangeiros ocasionam graves problemas ao meio ambiente como um todo, prejudicando a vida humana, a flora e a fauna. E, por conseguinte, recursos antes inesgotáveis tornam-se cada vez mais esgotados, como a perda da biodiversidade causada pelo desmatamento desenfreado, a perda dos recursos hídricos, a seca em várias regiões do país, assim como as enchentes, a escassez de alimentos, entre outros tantos problemas ambientais permitem que vários cientistas e pesquisadores reflitam sobre o papel da Ciência diante do agir do homem no mundo e nos conduz a mensurar, compreender e investigar a complexidade da temática ambiental na sociedade contemporânea.

Os estudos realizados por Hogan (2007) a respeito dos vários acidentes ambientais voltados à compreensão de como eles interferem nos aspectos econômicos, sociais e ambientais na sociedade moderna são uma referência ao estudo da temática ambiental. 
As crises ambientais causadas pelo ser humano provocam a alteração da natureza com dimensões globais que provocaram medidas governamentais e não governamentais, além de se constituírem como objeto de estudo para a ciência, trazendo questões epistemológicas, metodológicas, éticas e políticas que podem ser inseridas nos projetos pedagógicos curriculares dos cursos de Licenciatura visando à formação de professores nas Universidades.

Neste caso, a Universidade Federal de Rondônia (UNIR), como uma instituição da região norte, tem como função social formar professores que possam atuar com a temática ambiental na educação básica. Assim sendo, a Educação Ambiental contribui para esse processo formativo.

Esta investigação pretende responder às seguintes questões norteadoras: a) Os cursos de licenciatura da UNIR - campus de Porto Velho desenvolvem a temática ambiental? b) Quais temas ambientais têm sido priorizados pelos cursos de licenciatura da UNIR, campus de Porto Velho?

Para responder estas questões, este artigo tem como objetivo analisar como os cursos de licenciatura da UNIR, campus de Porto Velho desenvolvem a temática ambiental nos projetos pedagógicos e nos componentes curriculares e investigar quais temas são privilegiados pelos docentes. Inicialmente, apresentam-se os aspectos metodológicos elencando os procedimentos da coleta e da análise dos dados. Em seguida, aborda-se o referencial teórico a respeito da formação de professores na temática ambiental. E, finalmente, serão abordados os dados da temática ambiental nos cursos de Licenciatura no processo formativo de professores.

\section{DELINEAMENTO DA PESQUISA}

Esta pesquisa caracteriza-se como um "estudo de caso exploratório" em uma abordagem qualitativa realizada no campus da UNIR, cidade de Porto Velho.

Os dados foram coletados por meio da análise documental de sete projetos curriculares de cursos de licenciatura da UNIR, campus de Porto Velho, que consideram a temática ambiental em seus currículos, a saber: 
Licenciatura em Pedagogia, Ciências Sociais e História, pertencentes ao Núcleo ${ }^{3}$ de Ciências Humanas e no Núcleo de Ciências Exatas e da Terra, os cursos de Licenciatura em Geografia, Biologia, Química e Física.

Realizaram-se entrevistas semiestruturadas com 14 (quatorze) professores que trabalham com a temática ambiental, e para tanto, foram identificados nas suas falas pela letra "P" com os seus respectivos números.

A "Análise de Conteúdo" proposta por Bardin (2009) e as características da Rede ACES (2002) foram utilizadas para a análise dos projetos pedagógicos, dos planos pedagógicos das disciplinas ministradas e das entrevistas semiestruturadas que serviram para a identificação dos componentes relacionados à análise da temática ambiental, enquanto uma unidade de significação.

\section{A FORMAÇÃO DE PROFESSORES E A TEMÁTICA AMBIENTAL}

A educação é um fator primordial para a construção do conhecimento e exige dos professores uma formação voltada para o campo teórico e prático da organização dos cursos, objetivando trabalho educativo num processo dialético. Nesse aspecto, Saviani (1994) destaca que o trabalho educativo volta-se a conteúdos significativos da Educação que representam um processo de apropriação da própria humanidade e da sua história na qual ser humano está inserido.

Alguns teóricos entendem que a formação docente, deve estar presente nas aprendizagens da docência (MIZUKAMI, 2005; 2006), mas segundo Imbernón (2010) a mesma ocorre por meio de um processo contínuo que começa desde o início da vida escolar do professor, perpassa pela educação básica do futuro profissional, depois abrange o seu trabalho na docência, bem como, sua participação nas atividades pedagógicas. Por sua vez, Gatti (2010) compreende que a formação de professores deve ser

\footnotetext{
3 De acordo com o Art. 15 do Regimento "Os núcleos e os campus são órgãos acadêmicos que congregam os Departamentos e são responsáveis pela coordenação das funções de ensino, pesquisa e extensão, tanto em termos de planejamento, como em termos de execução e avaliação" (UNIR, PDI, 2008). O campus de Porto Velho possui uma estrutura de Núcleos: Ciências Humanas, Ciências Exatas e da Terra, Ciências Sociais Aplicadas, da Saúde e o de Tecnologia.
} 
guiada pelas exigências da sociedade que se refletem na prática pedagógica.

Em relação à formação de professores relacionada à temática ambiental no ensino superior, Leff (2001, p. 254) considera que a "[...] formação ambiental é pertinente para compreender a transformação da realidade causada pela problemática do desenvolvimento". Diante disso, os cursos universitários devem possibilitar um currículo ambiental que possa abranger os conteúdos voltados às realidades culturais e sociais.

Isto posto, no Brasil, a lei 9795 define a Educação ambiental como:

[...] um processo por meio dos quais o indivíduo e a coletividade constroem valores sociais, conhecimentos, habilidades, atitudes e competências voltadas para a conservação do meio ambiente, bem de uso comum do povo, essencial à sadia qualidade de vida e sua sustentabilidade (BRASIL, 1999, p. 1).

Deste modo, sugere-se aos educadores que definam como objetivos fundamentais para a implantação da educação ambiental, os valores que possam construir uma consciência crítica voltada para a participação de todos os acadêmicos, caracterizados pela constituição de um currículo que contemple os princípios propostos pela Lei.

Em seu Art. 11, a referida Lei institui que "a dimensão ambiental deve constar dos currículos de formação de professores, em todos os níveis e em todas as disciplinas" (BRASIL, 1999, p. 1), prevendo assim que as Universidades e os Institutos de Ensino Superior incluam a educação ambiental em disciplinas ou em conteúdos de forma interdisciplinar.

Neste entendimento, é imprescindível que os educadores ambientais estabeleçam uma interação com os educandos levando em conta o conhecimento, a considerarem os princípios éticos, estéticos e políticos em suas ações cotidianas (CARVALHO, 2006).

A função de ser um educador ambiental é a de proporcionar que os educandos participem de atividades voltadas ao contexto sócio-cultural e ambiental. A formação inclinada à Educação Ambiental busca no âmbito teórico e prático, componentes curriculares que abranjam conhecimentos, valores e atitudes relacionados às culturas ambientais, sociais e políticas 
entre os seres humanos (MORALES, 2012). Assim, os desafios relacionados ao saber ambiental devem ser pensados por meio dos saberes e de um currículo que privilegie a construção da educação ambiental na Universidade.

Silva (2002) compreende que o currículo é um "documento de identidade" porque tem seu discurso, sua ideologia, sua história, sua representação social na escolha dos conteúdos trabalhados pelos professores.

A compreensão de Zabalza (2004) é de que os currículos atuais nas universidades reforçam a efetivação das práticas docentes resultantes da interação do conhecimento com os significados educativos de ideias, valores, atitudes, crenças partilhadas nas universidades.

A respeito da incorporação da temática ambiental no currículo, Leff (1997) Gaudiano (1997), e Mercado (1997) entendem ser um caminho fundamental no ensino superior.

Leff (1997, p. 210) compreende que o currículo ambiental no Ensino Superior deve ser pensado a partir de temas relacionados ao saber ambiental:

As universidades devem realizar esforços para ir configurando os eixos temáticos que orientem o desenvolvimento do conhecimento para gerar um novo saber ambiental, capaz de ser transformado aos paradigmas e disciplinas tradicionais.

Deste modo, quando incorporados, os temas fazem parte de conhecimentos teóricos, metodológicos e práticos para a formação do educador ambiental nas Universidades.

Gaudiano (1997) destaca que os currículos nos cursos de licenciaturas devem possuir uma "reestruturação e ressignificação" nos conteúdos para a formação de professores no Ensino Superior por meio da interdisciplinaridade e a transdisciplinaridade.

Em relação à incorporação da temática ambiental nos currículos das universidades, Mercado (1997, p. 216) aponta quatro aspectos importantes: 
- considerar o ambiente em sua totalidade, tanto natural como o criado pelo homem com seus componentes ecológicos, políticos, econômicos e tecnológicos, sociais e legislativos, culturais e estéticos; - considerar a Educação Ambiental como um processo de toda a vida e não somente reduzida à escola;

- orientar-se com um enfoque de totalidade e interdisciplinaridade;

- colocar ênfase na participação ativa dos sujeitos para prevenir e resolver problemas ambientais, presentes e futuros.

Estes quatro aspectos são fundamentais para a formação dos educadores ambientais nos cursos de Licenciatura de modo interdisciplinar, crítico, aberto e criativo e que observem o campo epistemológico, metodológico para que ocorra o que se pode chamar de processo de Ambientalização Curricular4.

O termo Ambientalização Curricular surgiu com a finalidade de democratizar o conhecimento e possibilitar trocas de experiências entre os professores e acadêmicos, que resultou na definição do termo:

La ambientalización curricular es un processo continuo de producción cultural tendiente a la formación de profesionales comprometidos con la búsqueda plenamente de las mejores relaciones posibles entre la sociedad y la natureza, atendiendo a los valores de la justicia, la solidaridad y la equidad, aplicando los principios éticos universalmente reconocidos y el respeto a las diversidades (CIURANA; JUNYENT; ARBAT, 2003, p. 21, grifos nossos). ${ }^{5}$

A incorporação dessa temática é fundamental para analisar as práticas curriculares relacionadas aos aspectos culturais, promovendo um diálogo com as metodologias e nas práticas sociais trabalhadas nas diferentes universidades (OLIVEIRA JÚNIOR et al, 2003).

A partir desta caracterização, apresenta-se a seguir, o resultado da temática ambiental nos Cursos de licenciatura da UNIR, campus de Porto Velho-RO.

\footnotetext{
${ }^{4}$ A Rede de "Ambientalização Curricular dos Estudos Superiores (ACES)" foi constituída em 2002 com o objetivo de apresentar um projeto comum ao Programa ALFA da União Européia sob o título "Programa de Ambientalização Curricular do Ensino Superior". As Universidades participantes elaboraram dez características constitutivas de um currículo ambientalizado por meio de intervenções e análises do processo com um contrato firmado com onze universidades, sendo cinco européias e seis latino-americanas (CIURANA; JUNYENT; ARBAT, 2003).

5 A ambientalização curricular é um processo contínuo de produção cultuaral tendendo à formação de profissionais comprometidos com a busca das melhores relações possíveis entre sociedade e natureza, levando em conta os valores da justiça, da solidariedade e equidade, aplicando os princípios éticos universalmente reconhecidos e respeitanto as diversidades (tradução livre).
} 


\section{A TEMÁTICA AMBIENTAL NOS CURSOS DE LICENCIATURA DA UNIR}

A UNIR foi criada pela Lei 7.011 de 08 de Julho de 1982 com 0 propósito inicial de formar professores nas áreas de Educação Física, Letras, Pedagogia, História, Geografia, e Ciências (Habilitação em Matemática) que visava atender a enorme demanda de professores para atender a rede estadual de Ensino Fundamental e Médio do estado de Rondônia, bem como, formar bacharéis em Administração, Ciências Contábeis e Economia.

A UNIR acompanhou o crescimento do estado de Rondônia, desenvolvendo uma política de interiorização regional das atividades acadêmicas no quadriênio 1986-1989, através do "Primeiro Projeto Norte de Interiorização" que ampliou os cursos de graduação. Após os anos de 1990, implementou uma política de criação e capacitação do quadro docente para a realização de cursos de Mestrados e Doutorados Interinstitucionais, bem como o fortalecimento dos Cursos de Licenciatura.

O primeiro curso analisado é o de Licenciatura em Pedagogia cujo objetivo é o de formar professores para trabalhar na Educação, com habilitação nas séries iniciais "com vistas a contribuir para superação de exclusões sociais, étnico-raciais, econômicas, culturais, religiosas, políticas, ambientais e outras" (UNIR, CURSO DE PEDAGOGIA, 2008, p. 24, grifo nosso).

No curso, há aspectos relacionados com a temática ambiental, pertinente à realidade amazônica que pode ser observada na relação homem, sociedade e natureza, enfatizada pelas questões do multiculturalismo nas disciplinas "Educação dos Povos da Floresta" e a "Educação Ambiental e do Campo".

Os temas da disciplina "Educação dos Povos da Floresta" abordam a realidade cultural das comunidades tradicionais amazônicas com os valores culturais das comunidades tradicionais: índios, caboclos, quilombolas e seringueiros, nas relações homem, sociedade e natureza, que segundo o professor, abordam "a educação de ribeirinhos, indígenas, educação rural com a ênfase no compromisso com a transformação das relações sociedade-natureza, com a finalidade de analisar os aspectos da cultura amazônica na educação" (P1). À vista disso, os aspectos antropológicos 
trabalhados demonstram a formação de professores por meio do estudo e na prática dos saberes e da consciência ambiental.

Do mesmo modo, a disciplina "Educação Ambiental e do Campo" também se caracteriza pelos conteúdos antropológicos identificados pela diversidade cultural na Amazônia. Do mesmo modo, os saberes produzidos pelo multiculturalismo, pelas políticas ambientais do homem no campo, a biodiversidade, a degradação e a preservação ambiental, bem como, a qualidade de vida das populações estão presentes nos conteúdos da referida disciplina (UNIR, CURSO DE PEDAGOGIA, 2008, p. 50). Para o Professor "Os temas tratados estão focados na Educação Ambiental pela diversidade cultural referente à identidade dos povos tradicionais necessários para a aprendizagem ambiental" (P2).

Souza Lima e Knechtel (2012, p. 33) afirmam que "em sua perspectiva de análise, o multiculturalismo poderá referenciar práticas de Educação ambiental centradas na valorização dos saberes locais ou dos saberes dos estudantes, não apenas do educador acerca dos temas ambientais". Neste caso, o trabalho educativo observado pelas práticas multiculturais nestas duas disciplinas reforça as abordagens filosóficas como uma proposta que fundamenta a Educação Ambiental de modo interdisciplinar na prática educativa escolar.

O segundo curso analisado é o de Licenciatura em História, criado em 1982 caracteriza-se por privilegiar a história regional identificada pelas diferentes metodologias e teorias com ênfase na "preservação do patrimônio e assessorias nos setores culturais, artísticos e turísticos, uma vez que a formação do profissional de história se fundamenta no exercício da pesquisa" (UNIR, CURSO DE HISTÓRIA, 2005, p. 2).

As conjunturas históricas no campo de investigação são fundamentais para uma análise histórica e filosófica ambiental identificada pela disciplina de "História da Amazônia", refletindo os contextos históricos na formação amazônica. A disciplina apresenta os conteúdos do extrativismo da 
borrachab, nas relações sociais e econômicas das populações tradicionais, com o desenvolvimento da agropecuária, a indústria química para desenvolver os produtos naturais, ambientais que marcaram a história de colonização Amazônia. Neste caso, o Professor relaciona o extrativismo da borracha, a cultura, a alimentação dos caboclos à base de peixe e de farinha, os costumes alimentares e culturais nos estados do Acre, Amazonas, Pará e Rondônia diante das relações da colonização desde o momento em que os portugueses chegaram ao Brasil em seu contexto histórico da posse da terra, o tratamento dado pelos coronéis da borracha aos seringueiros: "Por conta das minhas pesquisas, eu fui sendo conduzido a abordar os aspectos ambientais e suas conexões com os processos históricos, explicando a nossa história da Amazônia" (P3).

Pode-se então destacar que as questões culturais enfatizadas no relato do professor denotam conteúdos relacionados ao meio social e econômico com a produção e a exploração da borracha, demonstram a cultura amazônica na história regional e ecológica:

[...] que então deve enfatizar a ação dos homens sobre a natureza e suas consequências, o que não pode ser feito sem o conhecimento dos limites impostos por essa natureza à continuidade ou não dessa ação e da forma como os homens se organizam para explorar o meio natural (FONSECA, 2004, p. 28).

A inserção da temática ambiental no curso de História pode ser analisada por questões que estão evidenciadas em algumas disciplinas no contexto amazônico.

Do mesmo modo, o curso de Licenciatura e Bacharelado em Ciências Sociais foi implantado em 2003 pelo Departamento de Sociologia/Filosofia, atualmente Departamento de Ciências Sociais com o objetivo de formar licenciados e bacharéis em Ciências Sociais com habilitação nas áreas de "Antropologia, Sociologia e Ciência Política" centrada em questões éticas, sociais por meio da formação específica do ensino com a pesquisa através

\footnotetext{
6 De acordo com Salati (1990), o período do ciclo da borracha (1840 a 1910), houve uma vinda de migrantes do Brasil para a Amazônia, contribuindo para a prosperidade econômica da região, mas que também trouxe modificações para a flora, a fauna e a cultura local. Depois do declínio da borracha, a economia entrou em decadência, causando danos à região amazônica.
} 
de conteúdos interdisciplinares com a realidade amazônica (UNIR, CURSO DE CIÊNCIAS SOCIAIS, 2006, p. 5).

A temática ambiental no curso de Ciências Sociais da UNIR vem ocorrendo por meio das disciplinas "Eletivas" em conteúdos que tratam da justiça, da ética e dos valores ambientais, trabalhados na interface com outras disciplinas, quando envolve os conteúdos relacionados à formação de um cientista social comprometido com a temática ambiental na universidade.

No curso, a temática ambiental está no campo da Ciência Política, que contempla o eixo social e político direcionado para as políticas públicas e sociais, ambientais e que foi contemplada na disciplina eletiva denominada de "Tópicos Especiais em Ciência Política" que teve como título "Integração Sul-América e o Planejamento Regional na Amazônia".

A disciplina tem como objetivo discutir os modelos de desenvolvimento, os projetos de construção das hidrelétricas, os impactos ambientais e geográficos do estado de Rondônia, a problemática da Amazônia e seus impactos nas comunidades tradicionais, investigar a complexidade do rio Madeira (Porto Velho-RO), avaliação da equidade ambiental e impactos socioeconômicos, as resistências sociais em processo com o Movimento dos Antingidos por Barragens (MAB), associações ribeirinhas e articulações dos povos indígenas (UNIR, CURSO DE CIÊNCIAS SOCIAIS, 2006, p. 27). Neste contexto, a fala do professor representa o seu trabalho educativo:

Eu trabalho com os conflitos sociais, as desigualdades sociais para identificar e demonstrar o paralelo social e ambiental no capitalismo à custa da incorporação dos recursos naturais da Amazônia. Também eu trabalho os conteúdos referentes à justiça ambiental considerando as desigualdades a respeito dos danos ambientais pelo alagamento das hidrelétricas de "Jirau e de Santo Antônio" aos trabalhadores de baixa renda, dos grupos raciais discriminados, das populações marginalizadas e mais vulneráveis, como os moradores atingidos pelas enchentes na cidade de Porto Velho (P4).

As questões apontadas pelo professor são fundamentais para a compreensão na formação de educandos no campo das Ciências Sociais, caracterizando que a temática ambiental na Amazônia deve ser trabalhada 
na perspectiva social, como por exemplo, a construção das hidrelétricas que modificam o espaço ambiental, fato que "dá origem a uma dívida ecológica" (ZHOURI, 2006, p. 151).

Garzon (2010, p. 9) considera que os empreendimentos das Hidrelétricas de Jirau e de Santo Antonio negligenciaram e omitiram o detalhamento das diretrizes que estavam constantes no Plano Básico Ambiental (PBAs), prejudicando os ribeirinhos do rio Madeira. Para ele, o empreendimento das Hidrelétricas trouxe prejuízos ao meio ambiente, à vida social e econômica das populações que vivem no entorno do rio, o que permite analisar pela ótica da justiça ambiental.

Neste caso, a justiça ambiental é necessária de ser estudada na formação de professores voltados aos problemas sociais. Identifica-se, assim, a relevância de realizar um trabalho educativo que demonstre a análise das desigualdades sociais evidenciadas nos espaços ambientais pelo uso e emprego de atividades de exploração madeireira.

Os temas relacionados com a história ambiental e a justiça ambiental na Amazônia são enfatizados respectivamente pelos cursos de licenciatura em História e Ciências Sociais, principalmente voltados às discussões dos conflitos relacionados com a construção das Usinas de Santo Antônio e Jirau.

Os três cursos analisados demonstram que a temática ambiental está sendo trabalhada para a formação de professores por meio da interdisciplinaridade e transdisciplinaridade com a educação ambiental. Assim, observou-se que o trabalho educativo contempla a temática ambiental desde a educação infantil ao ensino médio e considera os valores do conhecimento, da ética, a estética, os valores culturais, enfatizados pelo multiculturalismo, conforme afirmam Mendes et al (2012, p. 49) "a Educação ambiental quando procura entender a cultura e sua diversidade, contribui para um diálogo intra e extradisciplinar [...]".

Por conseguinte, ao valorizar os conteúdos culturais, os professores de licenciatura podem contribuir com a educação ambiental de forma crítica, refletindo o desenvolvimento da consciência e dos valores ambientais no contexto amazônico. 
Nesse sentido, os temas relacionados com a história ambiental e a justiça ambiental na Amazônia são enfatizados respectivamente pelos cursos de licenciatura em História e Ciências Sociais, principalmente os conflitos relacionados com a construção das Usinas de Santo Antônio e Jirau. Estes elementos podem ser compreendidos pela Educação ambiental crítica, enquanto uma proposta a ser trabalhada na formação de professores:

Educação Ambiental Crítica objetiva promover ambientes
educativos de mobilização desses processos de intervenção sobre a
realidade e seus problemas socioambientais, para que possamos
nestes ambientes superar as armadilhas paradigmáticas 10 e
propiciar um processo educativo (GUIMARÃES, 2004, p. 30).

A formação de professores nos cursos investigados no Núcleo de Ciências Humanas proporciona em sua análise uma visão crítica do materialismo histórico-dialético, de forma que os conteúdos ambientais são apresentados em vários contextos de contradição e nas lutas que ocorrem nas relações entre homem, sociedade e natureza, visando à formação dos educandos na Universidade.

O primeiro curso de licenciatura que pertence ao Núcleo de Ciências Exatas e da Terra analisado foi o de Geografia que também teve seu início na UNIR em 1982, com a finalidade de formar professores com licenciatura plena para atuação no ensino da Geografia no Estado de Rondônia, nos eixos "da organização do espaço, planejamento e gestão do território, meio ambiente e educação, orientados para a formação de técnicos, pesquisadores e professores competentes naquilo que concerne ao conhecimento geográfico" (UNIR, CURSO DE GEOGRAFIA, 2000, p. 1). Em relação às disciplinas do Curso relacionadas à temática ambiental foram a Geografia Econômica, a Hidrologia, Organização do Espaço Amazônico, Geografia da Amazônia, Geografia de Rondônia, Gestão e Análise Ambiental, Educação Ambiental.

A disciplina de "Geografia Econômica" cuja característica é trabalhar o espaço produzido pelo ser humano, diante da realidade na forma de pensar e dominar a natureza, conforme afirma o Professor: "O nosso trabalho na Geografia caminha para contribuir para a formatação de uma nova 
mentalidade, pois este ambiente que chamamos de ambiental é uma produção humana" (P5).

Nesse contexto, a disciplina "Organização do Espaço Amazônico" (7º período) destaca os conteúdos relacionados com a integração da Amazônia nos cenários mundial e nacional (UNIR, CURSO DE GEOGRAFIA, 2000, p. 21). Os aspectos culturais são trabalhados pelo Professor por identificar a espacialidade referente às condições humanas, sociais e ambientais que abarcam o viver na floresta como, por exemplo, o caboclo, oriundo dos nordestinos na Amazônia:

Eu tenho definido assim as minhas preocupações, na orientação de temas voltados para essas questões culturais, a respeito da condição do nordestino aqui na Amazônia, esse nordestino que conta, enfrenta a sua condição humana (P6).

Observa-se, na fala do professor, que ocorre um trabalho educativo por meio das representações espaciais culturais dos caboclos ribeirinhos que compõem o modo de vida na Amazônia. Deste modo, Barbero e Gautier (2005) caracterizam as questões culturais como fundamentais na educação ambiental, pois elas reforçam as identidades étnicas para a convivência das diferentes culturas. Logo, observa-se que há uma ênfase em trabalhar a geografia cultural na temática da espacialidade humana, bem como a análise da ocupação dos espaços urbanos e rurais pelos migrantes na Amazônia, desde o período do auge da borracha até o seu declínio, o que provocou a alteração do meio ambiente, das paisagens, e dos hábitos e costumes.

A disciplina de "Geografia da Amazônia" indica o trabalho educativo com a realidade amazônica em seu contexto histórico e geográfico por meio das políticas de ocupação na Amazônia relacionadas à colonização agrícola, diante dos impactos causados por ocupações desordenadas, além de identificar as questões de políticas de assentamento agrícola e a sustentabilidade ambiental, conforme relata o Professor:

Eu trabalho a questão da Floresta amazônica, o ordenamento e o Monitoramento Ambiental e Ecológico, alteração antrópica da Amazônica, os recursos florestais, o ordenamento territorial, o papel da floresta da regulação climática, os índices pluviométricos (P7). 
Então, o trabalho educativo desenvolvido pelo professor enfatiza os conflitos estabelecidos entre as comunidades tradicionais e a ideologia desenvolvimentista do governo federal, com projetos de expansão e ocupação das áreas da floresta amazônica por migrantes do sul, sudeste e nordeste, o desmatamento e a perda da biodiversidade amazônica com uma lógica do lucro instaurada na produção excessiva de pastagens para o desenvolvimento da agropecuária.

A manutenção dos espaços geográficos na Amazônia, especificamente em Rondônia corresponde à identificação de uma consciência ecológica, na luta pela preservação ambiental, cujo exemplo da luta contra o desmatamento no Acre é a história de Chico Mendes, considerado como um sujeito ecológico engajado nas lutas políticas, sociais e ambientais (CARVALHO, 2001).

Por sua vez, a disciplina de "Geografia de Rondônia" possui como objetivo "investigar a realidade do espaço rondoniense, a ocupação do território e o processo de colonização" (UNIR, CURSO DE GEOGRAFIA, 2000, p. 26) e os conteúdos abordam a temática ambiental nos aspectos da identidade local e regional, conforme afirma o Professor:

Eu enfatizo o meio físico em uma relação com o espaço geográfico amazônico com a Educação Ambiental, o olhar do homem sobre o meio ambiente ser determinante e indispensável para a construção de qualquer sociedade (P8).

Observa-se que o professor utiliza conteúdos relacionados ao espaço geográfico, também pode ser observado nos conteúdos das disciplinas de "Gestão Ambiental" e de Análise Ambiental e de Recursos Hídricos.

Os conteúdos se referem ao planejamento, à auditoria ambiental e sua relação com as políticas públicas, com os recursos físicos e naturais. Estes são trabalhados na disciplina de "Gestão ambiental" relacionando com o desmatamento, as queimadas e a degradação ambiental na Amazônia, especificamente na região de Rondônia, de modo que envolva a teoria com a prática da conservação no Brasil e na Amazônia.

A disciplina de "Análise Ambiental" diz respeito à utilização da cartografia para o meio ambiente, para análise da gestão e da análise 
ambiental, relacionados à bacia hidrográfica evidenciando os problemas inerentes à cidade de Porto Velho, que possui diversos igarapés totalmente poluídos por esgotos jogados pela população, conforme afirmativa do professor que trabalha com as duas disciplinas: "eu evidencio que a gestão das bacias diz respeito à ação do homem nas questões sociais, políticas e econômicas para com a natureza" (P9).

A temática dos Recursos Hídricos está presente na disciplina de "Hidrologia" (4 período) pelo estudo da gestão das águas, os conteúdos propostos enfatizam o gerenciamento e o planejamento a respeito do uso das águas, tendo a bacia hidrográfica como unidade de gestão e a valorização da Educação ambiental, conforme explica o Professor: "Eu enfatizo o porquê dos poços continuarem secando no início da chuva, explico o ciclo das águas, o período mais crítico e a gente consegue explicar a polvição" (P9). Estas afirmativas refletem a preocupação do professor em desenvolver as questões ambientais voltadas para a realidade da geografia física e humana.

Os conteúdos oriundos da gestão, da análise ambiental e dos recursos hídricos estão relacionados com os problemas ambientais referentes ao mau uso da produção e da manipulação dos bens capitalistas no estado de Rondônia e que são trabalhados na sala de aula, visando uma formação de professores no curso de Geografia da UNIR.

O curso de Licenciatura em Geografia possui a disciplina de "Educação Ambiental" que em seu currículo possui como objetivo:

Descrever os conteúdos relacionados com a Educação Ambiental no contexto histórico das relações homem, sociedade e natureza; Compreender a teoria e a prática da educação ambiental com as metodologias participativas; Monitorando e avaliando projetos de educação ambiental (UNIR, CURSO DE GEOGRAFIA, 2000, p. 15).

Nesta proposta, o professor enfatiza alguns conteúdos que possibilitam a formação dos acadêmicos na Universidade: "Eu trabalho a legislação, a prática de ensino e didática da geografia, a ética que prioriza a Educação ambiental, voltada para a ética e a cidadania ambiental" (P10). Deste modo, faz-nos compreender que a educação ambiental é formadora de 
cidadania planetária que se fundamenta nas reações sociais, éticas e como educação política (REIGOTA, 1994; CARVALHO, 2006).

Destarte pensar em uma Geografia com o pensamento crítico para a formação de professores na Educação ambiental, conforme afirma Costa (2009, p. 143) afirma:

A Geografia pensada assim, nessa busca por uma resposta à atual crise do nosso tempo, pode contribuir na sustentabilidade da Educação ambiental por meio do compromisso ético de promover mudanças de valores e atitudes, dentro do seu campo específico com diálogo com os outros saberes.

Ao refletir quais conteúdos devem ser trabalhados no curso de Geografia para a formação de professores, é necessário pensar uma epistemologia que reflita tanto as questões relacionadas ao meio ambiente físico e humano, considerando as relações entre o homem, sociedade e natureza em sua dinâmica social:

Pensar o ambiente em geografia é considerar a relação natureza/sociedade, uma conjunção complexa e conflituosa, que resulta do longo processo de socialização da natureza pelo homem. Processo este que, ao mesmo tempo em que transforma a natureza, transforma, também a natureza humana (SUERTEGARY, 2004, p. 4).

Neste caso, considera-se que os conteúdos trabalhados no curso de Geografia por meio da temática ambiental privilegiam elementos críticos que abordam as questões econômicas, sociais e ambientais visando à formação de educandos na relação homem, sociedade e natureza. E, por conseguinte, enfatiza-se o conhecimento ambiental por meio do estudo da espacialidade e territorialidade nas áreas da Geografia Física e Humana, procurando desenvolver a Ambientalização Curricular de modo que contemple a formação dos professores.

Estes elementos também são pensados no Curso de Licenciatura Biologia da UNIR, que foi criado em 1995, com as modalidades de Licenciatura e Bacharelado, objetivando a formação de biólogos direcionada ao meio ambiente, para a região amazônica que implicam nas especificidades da aprendizagem da temática ambiental demonstrada pela biodiversidade da floresta amazônica: 
[...] na complexa teia da vida, a diversidade dos seres vivos e a importância de cada espécie na manutenção do equilíbrio ecológico, dos ecossistemas e das populações tradicionais com suas culturas próprias, especialmente daqueles presentes na região amazônica (UNIR, CURSO DE BIOLOGIA, 2002, p. 2).

Na organização do currículo do curso de Biologia, a temática ambiental está contemplada nas disciplinas de: "Liminologia", "Ecologia I" (5 período) e "Ecologia II" (6 período), "Biologia da Conservação" (60 período), "Ecologia da Amazônia" (7 período) e "Ecologia de Campo" (8 período). As disciplinas "Botânica", "Zoologia", "Tópicos Especiais em Ecologia" e "Geologia" também abordam questões relacionadas à temática ambiental.

De acordo com os professores entrevistados, deve-se priorizar o trabalho com a temática dos recursos hídricos, reforçando a hipótese de que é necessário administrar adequadamente os elementos do manejo e da gestão da água na cidade de Porto Velho, no que se refere à contaminação dos poços na região Amazônica e a contaminação dos metais pesados, como é o caso do mercúrio utilizado pelos garimpeiros no rio Madeira. Assim, o uso do mercúrio nas dragas do rio Madeira para a exploração do ouro provoca muita contaminação de peixes, afetando sensivelmente o ecossistema, atingindo diretamente a população ribeirinha que depende, essencialmente, do consumo dos peixes para o seu sustento.

A temática da preservação ambiental tem sido trabalhada com as

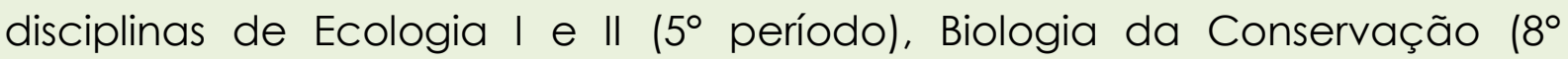
período), Ecologia da Amazônia ( $8^{\circ}$ período) e Ecologia de Campo (8 período) no curso de Biologia. Estas disciplinas são consideradas como obrigatórias no curso de Biologia, possuem conteúdos relacionados à temática da preservação ambiental, à compreensão dos ecossistemas de sua interação entre os fatores bióticos e abióticos, às comunidades e suas estruturas no meio das regulações e territorialidade.

Os conteúdos estão relacionados com a biodiversidade no contexto do crescimento das comunidades ecológicas, nos seus equilíbrios e desequilíbrios ambientais, conforme relato do Professor: "Eu trabalho com 
aspectos ecológicos relacionados à conservação da biodiversidade, pois a manutenção da floresta implica em cuidar de quem está nela, como exemplo os animais e a floresta, e aqueles que dependem dela, os humanos" (P11).

A disciplina de Ecologia de $\mathrm{Campo}^{7}$ caracteriza-se por investigar os processos ecológicos que tem como foco principal o processo ecológico, o comportamento da biodiversidade amazônica, a organização da fauna e da flora, relacionada à conservação, ao manejo e à manutenção das espécies amazônicas, com foco da interdisdisciplinaridade no curso de Biologia. Assim, "eu trabalho com os temas da manutenção da floresta e das espécies vegetais, minerais e animais" (P12).

As relações entre o ser humano e a constituição da vida animal e vegetal, também podem ser observadas na disciplina "Biologia da Conservação" que ressalta o estudo com as unidades de conservação de Rondônia, a biodiversidade e as ameaças com a degradação e a polvição ambiental da preservação, da conservação ambiental que afetam o bioma amazônico e seus aspectos com as populações amazônicas.

O trabalho com a preservação e conservação ambiental referente à floresta amazônica pertence ao manejo e à manutenção das espécies e tem a finalidade de promover a interação dos conhecimentos da teoria com a prática, nas universidades e nos grandes centros de Pesquisa na Amazônia. Assim, segundo o relato do professor: "O biólogo formado na UNIR deve conhecer os impactos não só da hidrelétrica, mas de rodovia, de pavimentação de rodovias, ou seja, como conservar a biodiversidade" (P12).

No currículo do curso de Licenciatura em Biologia destacam-se os seguintes temas: preservação dos recursos naturais, a biodiversidade na Amazônia de origem local, regional e global de modo interdisciplinar pelos professores, além de temas que proporcionam o debate e a reflexão crítica,

\footnotetext{
7 Para o desenvolvimento das atividades acadêmicas referentes a essa disciplina, o curso de Biologia dispõe de uma estação ecológica, a "Estação Ecológica Cuniã" localizada a 110 $\mathrm{km}$ de Porto Velho na Rodovia $319 \mathrm{com}$ o objetivo de trabalhar e investigar a natureza e suas relações com a Biologia (UNIR, CURSO DE BIOLOGIA, 2002).
} 
considerados fundamentais para o desenvolvimento do saber ambiental, conforme enfatizam Araújo e Bizzo (2005, p. 2) a respeito da inserção da problemática ambiental em sala de aula:

Portanto, no contexto de sala de aula, não se pode inserir a problemática ambiental exclusivamente como derivação do aproveitamento dos recursos naturais, redução da poluição etc., mas, também, das transformações sociais que historicamente vêm sendo construídas e da conduta social que o momento exige. Portanto, para alcançar os efeitos na educação básica, é necessário inserir na formação inicial dos professores a questão ambiental a partir da contradição instituída entre o modelo de desenvolvimento civilizatório adotado pelo ser humano, diante do fascínio do mundo industrializado, e a sustentabilidade por parte dos ecossistemas para esse tipo de desenvolvimento.

Considera-se que o educador ambiental no campo da Biologia seja capaz de articular os diversos tipos de conhecimentos, visando uma formação consciente e crítica da realidade sócioambiental (GUIMARÃES, 2004).

Com isso, torna-se evidente a característica da "contextualização (local-global-local/global-local-global)" com conteúdos relacionados à conservação dos biomas, aos impactos ocasionados pelo desmatamento e pelas aberturas de novas estradas. Considera-se ainda, que com a construção das hidrelétricas de Jirau e Santo Antonio no rio Madeira ocorram muitos impactos para o meio ambiente em Rondônia.

Outro curso investigado foi o de Licenciatura em Química, criado em 2000 com a finalidade de formar professores de Química no estado de Rondônia, que comprovam o trabalho com a biodiversidade amazônica e o reconhecimento do estudo da fauna e da flora para a investigação científica na área da saúde e preservação ambiental (UNIR, CURSO DE QUÍMICA, 2005).

Existem duas disciplinas trabalhadas na Licenciatura em Química: a "Química Ambiental" e a "Química dos Produtos Naturais". A primeira está centrada na temática da polvição em geral, e especificamente, os polventes tóxicos na água, por meio de seminários temáticos, com conteúdos de Educação Ambiental direcionada à preservação ambiental e que ressalta a necessidade de desenvolver os conhecimentos científicos, 
voltados para a Química Ambiental visando à preparação dos futuros professores de Química.

A temática da biodiversidade é desenvolvida na disciplina de "Química dos Produtos Naturais", com conteúdos a respeito da análise dos produtos naturais provenientes da flora amazônica e que são desenvolvidos no laboratório de Química Natural (UNIR, CURSO DE QUÍMICA, 2005),

Os conteúdos apresentados pelo professor dizem respeito ao estudo das plantas em seu habitat natural para que os alunos compreendam a importância da preservação ambiental: "é importantíssimo manter a floresta em pé, mostrar como a biodiversidade é necessária para desenvolver a região Amazônica" (P13). Desse modo, a escolha da temática da biodiversidade caracterizada pelo professor em seu relato aponta para a necessidade de preservar o meio ambiente natural.

Assim, de acordo com Zuin (2011) as intervenções humanas no campo ambiental devem necessariamente se concretizar de modo justo, equitativo e solidário, relacionado ao estoque de capital e dos usos da tecnologia industrial, incluindo os problemas químicos que afetam o meio ambiente, e como tal, devem ser trabalhados no processo formativo. Do mesmo modo, a autora destaca também:

\footnotetext{
Diante deste contexto, alguns dos desafios que se colocam vão da necessária postura crítico-reflexiva da (o) professor(a) em formação inicial ou continuada de Química, que se coloque como coresponsável no processo de formação profissional, à participação destas(es) e outros sujeitos pedagógicos implicados da comunidade universitária, das múltiplas redes de poderes, saberes e fazeres em constante movimento, para a construção de um currículo ambientalizado no cotidiano das IES (ZUIN, 2008, p. 9).
}

Esta afirmativa demonstra que tais elementos são significativos para a formação de professores de Química, e como tal, ressalta-se o compromisso dos professores da UNIR para desenvolver um trabalho educativo com disciplinas de "Química Ambiental" e "Química dos Produtos Naturais", além de discutir em Seminários realizados nas semanas pedagógicas.

As características de ambientalização de "levar em conta o sujeito na construção do conhecimento", pois o curso busca formar professores de Química que estejam preocupados com a biodiversidade amazônica. Esta 
constatação caracteriza-se pela identidade na formação de pessoas críticas para atuar na sociedade amazônica.

E, finalmente o Curso de Licenciatura Plena em Física (2004) que tem "por finalidade contribuir para o atendimento às demandas da sociedade em sua área de atuação, bem como, para o desenvolvimento sustentável da região amazônica e do país" (UNIR, CURSO DE FíSICA, 2006, p. 9). Neste caso, a constituição do campo da Física nas Ciências Naturais, requer que o conhecimento esteja voltado para fins pacíficos, de natureza ecológica para a melhoria da vida planetária e na aprendizagem da temática ambiental.

Neste curso, observa-se que a disciplina "Física Ambiental" tem como objetivo "descrever as questões ambientais e os seus reflexos na problemática dos impactos ambientais" (UNIR, CURSO DE FíSICA, 2006, p. 1). Ela possui conteúdos identificados com a energia ambiental e tratam de questões relacionadas à poluição ambiental, como as Usinas que de fato beneficiarão as demandas energéticas do centro sul, cujo foco está no aumento da industrialização.

A constatação é de que a disciplina de "Física Ambiental conduz às discussões da Energia ambiental e como tal é necessária para o desenvolvimento das relações entre o homem e a sociedade" (P14), enfatizada pelo professor por meio das discussões referentes às construções das hidrelétricas de Santo Antônio e Jirau no rio Madeira.

É fundamental pensarmos em um ensino de Física que compreenda a temática ambiental relevante e incorporada na teoria e na prática no processo educativo, mas que pode ser analisada em um contexto da complexidade na relação homem, sociedade e natureza, tal como apontam Silva e Carvalho (2012, p. 372):

Contudo, em relação ao ensino de Física, há vários aspectos que parecem dificultar a realização de atividades de ensino que incorporem os questionamentos colocados pelo movimento ambientalista. Dentre essas dificuldades, certamente destacam-se aquelas diretamente relacionadas com a possibilidade de abordagens mais complexas da relação homem e natureza. Nesse sentido, ainda prevalece em muitas práticas de ensino de Física a idéia de um conhecimento científico factual e conceitual. 
As abordagens referentes à temática da energia na região norte por meio das construções das hidrelétricas no rio Madeira são imprescindíveis no currículo de Licenciatura em Física.

$\mathrm{Na}$ análise do Projeto Pedagógico, o professor aponta que o curso de Física tem em parte questões relacionadas ao processo de Ambientalização Curricular. Neste caso, é primordial para a formação dos acadêmicos, realizar um trabalho educativo por meio de temas relacionados aos problemas da Amazônia, relacionando com as questões energéticas, enquanto um tema ambiental voltado para o desenvolvimento econômico mundial, diante da grande perda da biodiversidade, além dos danos ambientais que elas representam (MORET, 2009).

\section{CONSIDERAÇÕES FINAIS}

Os cursos de Licenciatura do campus de Porto Velho investigados, possuem características de Ambientalização curricular em seus projetos pedagógicos e no desenvolvimento das ações pedagógicas dos professores.

No curso de Pedagogia os conteúdos priorizados referem-se ao multiculturalismo e da cultura amazônica na teoria e na ação pedagógica para a formação de professores das séries iniciais. Percebe-se que a Educação Ambiental poderia ser mais enfatizada no curso, pois permite o caminho para a condução de uma formação de professores das séries iniciais, considerando ser relevante ao ensino e à aprendizagem dos alunos nas escolas de Rondônia.

No curso de Ciências Sociais, os conteúdos referentes à relação homem, sociedade e natureza integram a temática da justiça ambiental por meio de debates em Seminários e pesquisas, no que diz respeito à realidade de Rondônia, sobretudo, do município de Porto Velho, identificado nas hidrelétricas de Jirau e de Santo Antônio no rio Madeira.

No curso de História, os conteúdos são trabalhados na disciplina de "História da Amazônia" referente aos processos históricos da Amazônia relacionados à produção da borracha. A temática ambiental revela que o 
curso insere as discussões na relação que envolve a sociedade e a natureza e que poderia ser de modo interdisciplinar.

Por sua vez, o curso de Geografia caracteriza-se por desenvolver conteúdos relacionados à espacialidade e à territorialidade ambiental, desde a questão da organização do espaço amazônico até as questões da gestão e da análise ambiental. Por sua vez, as temáticas dos recursos hídricos, os conflitos com a terra, as configurações espaciais advindas do processo migratório do nordeste, sul, centro-oeste e norte, a construção das hidrelétricas no rio Madeira, a problemática do desmatamento e as questões climáticas estão inseridas no processo da Ambientalização Curricular.

A inserção da temática ambiental no curso de Biologia vem ocorrendo pela ótica da biodiversidade amazônica, com ênfase na conservação e na preservação ambiental como os recursos hídricos e da polvição ambiental, relacionados às bacias hidrográficas de Rondônia, sobretudo no rio Madeira, em que as atividades de garimpo ainda estão presentes. Os impactos ambientais produzidos pela exploração amazônica são fundamentais para a formação de licenciados da Biologia na ótica da proteção e preservação da natureza, da floresta amazônica, da fauna e da flora, enfim, da vida.

Os cursos de Biologia e o de Geografia fortalecem o compromisso com as questões da complexidade da temática ambiental, entendendo ser ela necessária para a compreensão da biodiversidade na Amazônia para a manutenção da vida planetária. Estes dois cursos demonstram a preocupação em ensinar a temática ambiental com conteúdos relacionados à preservação, conservação, espacialidade e a biodiversidade amazônica.

Os cursos de licenciatura de Biologia, Geografia, Química e Física enfatizam questões a respeito da polvição ambiental nas fronteiras agrícolas, a exploração mineral realizada pelos garimpos de ouro no rio Madeira, a exploração da cassiterita na região de Ariquemes e ainda as queimadas, o desmatamento, a polvição dos rios, o aumento da produção do lixo e a falta de limpeza nas cidades. 
Outro ponto em comum entre os cursos de Geografia, Pedagogia e Biologia são as questões pertinentes ao estudo da cultura amazônica, referentes às populações tradicionais, elencando fatores como: a forma de vida dessas populações, dos caboclos, dos indígenas e, enfim, dos ribeirinhos que buscam a preservação da natureza.

Observa-se ainda, a intenção de produzir o "saber ambiental" diante das questões relacionadas à temática ambiental, enfocando a formação de licenciados para atuarem como professores. Desse modo, a temática dos impactos da construção da hidrelétrica de Jirau e de Santo Antônio no rio Madeira representam a necessidade de trabalhar conteúdos que enfatizem a justiça ambiental, bem como o multiculturalismo diante do desafio da manutenção da biodiversidade amazônica.

As análises apontam que os cursos de Licenciatura no campus da UNIR de Porto Velho trabalham com temas ambientais que despertam interesse dos acadêmicos, de modo que sua relevância é fundamental na formação de professores. Por outro lado, por ser uma Instituição formadora de senso crítico, que veicula conhecimentos e saberes, percebe-se que há uma necessidade de maior integração das disciplinas dos cursos de licenciatura da UNIR de modo interdisciplinar. É relevante na formação de professores, que se realize discussões que analisem a globalização e o avanço tecnológico, diante de situações complexas, facilitando assim a compreensão da abrangência de diversos temas.

Portanto, pode-se constatar que no campus UNIR de Porto Velho, os cursos de licenciatura investigados apresentam características de Ambientalização Curricular relacionadas ao "compromisso com as transformações nas relações sociedade-natureza"; "contextualização localglobal-local, global local-global"; "levar em conta o sujeito na construção do conhecimento" "considerar os aspectos cognitivos e afetivos, éticos e estéticos". Estas características podem ser mais desenvolvidas no processo de formação de professores por meio da Ambientalização curricular, e como tal, pode ser um caminho epistemológico para serem analisadas e investigadas as problemáticas locais e regionais, considerando os aspectos 
do multiculturalismo, da polvição e da degradação, da biodiversidade, da espacialidade e da territorialidade, da justiça ambiental e dos contextos históricos ambientais regionais demonstrados pelos currículos e práticas dos professores para a formação de professores no campo da Educação ambiental na Amazônia.

De uma maneira geral, os cursos de licenciatura da UNIR proporcionam reflexões em torno de sua própria prática docente a respeito da temática ambiental. Relevante considerar que a Educação Ambiental deveria ser trabalhada de modo interdisciplinar, de modo que há necessidade de ampliar a discussão da temática, principalmente, em torno da Bioética.

Ademais, sugere-se que as questões socioambientais nesta era contemporânea, evidenciem-se cada vez mais com discussões na sociedade, sendo necessária a inserção da temática nos currículos de licenciatura no Ensino Superior de modo geral. Contudo, ainda é importante que ocorra uma maior inerdisciplinariedade por meio da Educação Ambiental crítica, com a finalidade de contribuir para a formação de professores na sociedade contemporânea.

\section{REFERÊNCIAS}

ARAÚJO, M. I. O.; BIZZO, N. O discurso da sustentabilidade, educação ambiental e a formação de professores de Biologia. Enseñanza de LasCiencias. 2005; número extra. VII Congreso: 1-5.

BARBERO, J. M.; GAUTIER, A. M. O. Políticas de multiculturalidad y desubicaciones de lo popular. In: MATO, D.; Cultura política y sociedad: perspectivas lationoamericanas. CLACSO, Argentina, 2005, p. 181-197.

BARDIN, L. Análise de Conteúdo. Tradução de Luis Antero Reto e Augusto Pinheiro. Lisboa, Portugal: Edições 70, 2009.

BRASIL. Lei $\mathbf{n}^{\circ}$ 9795/1999. Dispõe sobre a educação ambiental, institui a Política Nacional de Educação Ambiental e dá outras providências.

CARVALHO, I. C. M. A invenção do sujeito ecológico: sentidos e trajetórias em Educação Ambiental. 2001, 411 f. Tese (Doutorado em Educação) Universidade Federal do Rio Grande do Sul, Porto Alegre, 2001. 
CARVALHO, L. M. de. A temática ambiental e o processo educativo: dimensões e abordagens. In: CINQUETTI, H. C. S.; LOGAREZZI, A. Consumo e resíduo: Fundamentos para o trabalho educativo. São Paulo: Edufscar, 2006, p. 19-41.

CIURANA, A. M. G. de; JUNYENT, M.; BAU, E. A. Características de la ambientalización curricular: Modelo ACES. In: JUNYENT, M.; CIURANA, A. M. G. de, BAU, E. A (eds.) Ambientalización Curricular de los Estúdios Superiores. Proceso de caracterización de la Ambientalización curricular de los estudios universitarios. Girona: Universitat de Girona, Red ACES, 2003. v. 2, p. 15- 32.

COSTA, F. J. C. Educação Ambiental e Cidadania: umacontribuição da Geografia cultural numa perspectiva fenomenológica. In: SANTOS, E. da C. (org.). Geografia e Educação Ambiental: reflexões epistemológicas. Manaus: Editora da Universidade Federal do Amazonas, 2009, p. 50-62.

FONSECA, D. R. da. Pesca e abastecimento na colonização da Amazônia, 2004, 2 v., Tese (Doutorado em Desenvolvimento Sustentável do Trópico Úmido) Universidade Federal do Pará, Belém, 2004.

GARZON, L. F. N. Desestruturação social e ambiental das comunidades ribeirinhas urbanas e rurais no município de Porto Velho. Porto Velho: Universidade Federal de Rondônia, Programa Institucional de Bolsas de Extensão (PIBEX UNIR), 2010.

GATTI, B. A. Formação de professores no Brasil: características e problemas. Educ. Soc., Campinas, v. 31, n. 113, p. 1355-1379, out.-dez. 2010.

GAUDIANO, E. G. La dimension ambiental: convergência o disyuntiva en el currriculum universitário. In. ALBA, A. (org.). El curriculum universitário: de cara al nuevo milênio. 2 ed. México: Universidad Nacional Autônoma de México, 1997, p. 199-204.

GUIMARÃES, M. Educação ambiental crítica. In: LAYRARGUES, P. P. (coord.). Identidades da educação ambiental brasileira. Brasília: Ministério do Meio Ambiente, Diretoria de Educação Ambiental, 2004.

HOGAN, D. J. População e Meio Ambiente: a emergência de um novo campo de estudos. In: HOGAN, Daniel Joseph (org.). Dinâmica populacional e mudança ambiental: cenários para o desenvolvimento brasileiro.

Campinas: Núcleo de Estudos de População-Nepo, Unicamp, 2007, p. 13-57.

IMBERNÓN, F. Formação docente e profissional: formar-se para a mudança e a incerteza. 8. ed. São Paulo: Cortez, 2010.

LEFF, E. Ambiente, interdisciplinariedad y currículum universitário: la educación superior en la perspectiva del desarrolho sustentable. In: ALBA, A. 
(org.) El curriculum universitário: de cara al nuevo milênio. México: Universidad Nacional Autónoma de México, 1997, p. 205-211.

LEFF, E. Saber ambiental: sustentabilidade, racionalidade, complexidade e poder. Petrópolis: Vozes, 2001.

MENDES FILHO, J. T. et al. O Sentido da diversidade sociocultural na Educação Ambiental. In: MORALES, A. G. et al (orgs.) Educação ambiental e multiculturalismo. Ponta Grossa: Editora da UEPG, 2012, p. 37-56.

MERCADO, M. T. B. Dimensión ambiental y curriculum universitário. In. ALBA, A. (org.). El curriculum universitário: de cara al nuevo milênio. México: Universidad Nacional Autónoma de México, 1997, p. 212-219.

MIZUKAMI, M.G. Aprendizagem da docência: professores formadores. Revista E-Curriculum, São Paulo, v. 1, n. 1, dez. - jul. 2005-2006

MORALES, A. G. A formação do profissional educador ambiental: reflexões, possibilidades e constatações. 2. ed. Ponta Grossa: UEPG, 2012.

MORET, A. de S. Desafios ao setor elétrico de Rondônia, como a biomassa sustentável pode contribuir para o aumento da oferta de eletricidade: 0 caso dos resíduos agrícolas. CONGRESSO BRASILEIRO DE PLANEJAMENTO ENERGÉTICO, 4., 2004, Itajubá. Anais eletrônicos..., Itajubá: UNIFEI/SBPE, 2004. Disponível em: http://www.seeds.usp.br. Acesso em: 20 nov. 2010.

OLIVEIRA JÚNIOR, W. et al. As 10 características em um diagrama circular. In: JUYENT, M.; CIURANA, A M. G.; ARBAT, E. (Eds.) Processo de Caracterización de laambientalización curricular de losestudiosUniversitarios. Girona: Rede ACES, 2003. v. 2, p. 35-55.

REIGOTA, M. O que é Educação Ambiental. São Paulo: Brasiliense, 1996.

SALATI, E. Modificações da Amazônia nos últimos 300 anos: suas conseqüências sociais e ecológicas. In: BRITO, S. de S. (org.) Desafio Amazônico: o futuro da civilização dos trópicos. Brasília: UnB, CNPq ,1990, p. 25-46.

SAVIANI, D. O trabalho como princípio educativo frente às novas tecnologias. In: FERRETTI, C.J. et al (Org.). Novas tecnologias, trabalho e educação. Petrópolis: Vozes, 1994, p. 151-168.

SILVA, L. F.; CARVALHO, L. M. de. A temática ambiental e o ensino de física: as diferentes compreensões dos professores de física em formação inicial.

Ciência \& Educação, v. 18, n. 2, p. 369-383, 2012.

SILVA, T. T. da. Documentos de Identidade: uma introdução às teorias do currículo. Belo Horizonte: Autêntica, 2002. 
SOUZA LIMA, J. E.; KNECHTEL, M. do R. O. Multiculturalismo e educação ambiental: dois campos de coexistência das racionalidades culturais e ambientais. In: MORALES, A. G. et al (orgs.) Educação ambiental e multiculturalismo. Ponta Grossa: Editora da UEPG, 2012, p. 27- 35.

SUERTEGARY, D. M. A. Ambiência e pensamento complexo: ressignific(ação) da Geografia. In: GALENO, A.; SILVA, A. A. D. da. Geografia ciência do complexus: ensaios transdicisplinares. Porto Alegre: Sulina, 2004.

UNIVERSIDADE FEDERAL DE RONDÔNIA. Plano de Desenvolvimento Institucional. Porto Velho: 2008.

UNIVERSIDADE FEDERAL DE RONDÔNIA. Departamento de Biologia. Projeto Pedagógico do Curso de Biologia. Porto Velho: UNIR, 2002.

UNIVERSIDADE FEDERAL DE RONDÔNIA. Departamento de Ciências Sociais. Projeto Pedagógico do Curso de Ciências Sociais. Porto Velho: UNIR, 2006.

UNIVERSIDADE FEDERAL DE RONDÔNIA. Departamento de Física. Projeto Político-Pedagógico do Curso de Física. Porto Velho: UNIR, 2006.

UNIVERSIDADE FEDERAL DE RONDÔNIA. Departamento de Geografia. Projeto Pedagógico do Curso de Geografia. Porto Velho: UNIR, 2000.

UNIVERSIDADE FEDERAL DE RONDÔNIA. Departamento de História. Projeto Pedagógico do Curso de História. Porto Velho: UNIR, 2005.

UNIVERSIDADE FEDERAL DE RONDÔNIA. Departamento de Ciências da Educação. Projeto Político-Pedagógico do Curso de Pedagogia. Porto Velho: UNIR, 2008.

UNIVERSIDADE FEDERAL DE RONDÔNIA. Departamento de Química. Projeto Pedagógico do Curso de Química. Porto Velho: UNIR, 2005.

ZABALZA, M. O ensino Universitário: seu cenário e seus protagonistas. Tradução Ernani Rosa-Porto. Porto Alegre: Artmed, 2004.

ZHOURI, A. O Ativismo transnacional pela Amazônia: entre a ecologia política e o ambientalismo de resultados. Horizontes Antropológicos, Porto Alegre, ano 12, n. 25, p. 139-169, jan./jun. 2006.

ZUIN, V. G. Trajetórias em formação docente: da química verde à ambientalização curricular, Caxambu, ANPED, 2008. --Int.pdf>

ZUIN, V. G. A Inserção da dimensão ambiental na formação de professores de Química. Campinas: Átomo, 2011. 